\title{
Arginine Esterase in Gystic Fibrosis of the Pancreas
}

\author{
G. J. S. Rao and Henry L. Nadler ${ }^{[19]}$
}

Division of Genetics, Children's Memorial Hospital, Department of Pediatrics, Northwestern University, Chicago, Illinois, USA

\section{Extract}

Arginine esterase activity in chloroform-ellagic acid-treated plasma from 11 patients with cystic fibrosis (CF) and 12 age-matched control subjects has been resolved into its component fractions by ion exchange chromatography on DEAE-Sephadex and electrofocusing on polyacrylamide gels. The activity can be resolved into two fractions by chromatography, one of which is inhibited by soybean trypsin inhibitor (STI) and the other of which is not inhibited by STI. In plasma of CF patients, the fraction of activity inhibited by STI is reduced to approximately $30 \%$ of the corresponding fraction in control plasma. In contrast, the fraction of activity resistant to inhibition by STI did not show any significant quantitative differences between control and CF plasma samples.

Analysis of the plasma samples by electrofocusing on $5 \%$ polyacrylamide gels in the range of $\mathrm{pH} 5.0-8.0$ and subsequent staining for arginine esterase activity showed qualitative differences between control and CF plasma samples. Six activity bands could be detected in control samples, whereas five bands were detected in CF samples. Eight samples had one type of band missing, two had another type of band missing, and one had yet another type of band missing. All of these bands were restricted to a narrow $\mathrm{pH}$ zone in the center of the gel.

These data are consistent with and extend our earlier reports of differences in arginine esterase activity between plasma samples of CF patients and control subjects. The demonstration of the absence of a single band of arginine esterase activity is consistent with the absence of a specific arginine esterase isoenzyme in patients with CF.

\section{Speculation}

The deficiency of arginine esterase in patients with cystic fibrosis may account for the presence of "factors" in saliva, plasma, and fibroblasts of these patients and consequently for the clinical manifestations of the disease. 


\section{Introduction}

Cystic fibrosis (CF) is an autosomal recessive disorder in which the beic basic defect remains unknown. Numerous theories including alterations in
ion transport, glycoprotein structure and membrane permeability $(5,6)$ have ion transport, glycoprotein structure and membrane permeability $(5,6)$ have of $C F$ will emerge from some of the approaches currently being taken (5).

It has been observed by several investigators that saliva (11) and serum $(1,14)$ of these patients contain "factors" which appear to be characteristic of the disease. . The "factor" in saliva inhibits sodium reabsorption in rat parotid glands (11). The "factor" in serum induces dyskinesis in ciliary preparations from rabbit trachea (14) and oyster gills (1). The "factors" in saliva and serum are nondialyzable, have a net positive charge at neutral $\mathrm{pH}$, are inactive in the presence of negatively charged polymers such as heparin $(1,11)$ and contain protein moieties. We have postulated (12) that the presence of these "factors" is due to the deficiency of enzymic activity similar to trypsin. Accordingly, we have shown that saliva and plasma of patients with CF are deficient in arginine esterase activity $(12,13)$. We have also postulated (13) that one of the several types of the arginine esterases might be totally absent in plasm of patients with CF. The present study demonstrates qualitative andquantitative differences in arginine esterase activity in plasma and fractions of plasma from controls and patients with CF.

\section{Materials and Methods}

Blood samples were collected from 11 patients with CF and 12 agematched controls after obtaining informed consent. $9.0 \mathrm{ml}$ blood was mixed with $1.0 \mathrm{ml}$ of $3.8 \%$ sodium citrate in plastic tubes. The plasma was separated by centrifugation at $4 \mathrm{O}^{\circ} \mathrm{C}$ and the samples were used immediately separated by centrifugation at $40 \mathrm{C}$ and the samples were used immediately
or stored at $-70^{\circ} \mathrm{C}$ until use. All samples were handled either in plasticor stored at $-70^{\circ} \mathrm{C}$ until use. All samples were handled either in plastic-
ware or siliconized glassware. Plasma was treated with chloroform-ellagic ware or siliconized glassware. Plasma was treated with chlor

The ellagic acid activated plasma was analyzed by chromatography on DEAE-Sephadex columns at $\mathrm{pH} 8.0$ and by electrofocusing on polyacrylamide gels. The sample for chromatography was prepared as follows. $6.0 \mathrm{ml}$ of activated plasma was chilled to $4^{\circ} \mathrm{C}$ in an ice bath and solid ammonium sulfate was added under stirring to $25 \%$ saturation. After 15 mins it was centrifuged and the precipitate discarded. Solid ammonium sulfate was added to the supernatant to $50 \%$ saturation, and centrifuged at $30,000 \mathrm{xg}$ for 15 mins at $4^{\circ} \mathrm{C}$. The precipitate was dissolved in a small volume of water and desalted on a column of Sephadex G-50 equilibrated with $5 \mathrm{mM}$ phosphate buffer, pH 8.0. The desalted samples were used for chromatographic analysis. Another aliquot $(1.0 \mathrm{ml})$ of the ellagic acid activated plasma was passed through a Sephadex G-50 column equilibrated with $5 \mathrm{mM}$ phosphate buffer, $\mathrm{pH} 8.0$. The Sephadex eluate was used in polyacrylamide gel electrofocusing analyses.

No significant loss of arginine esterase activity was observed during the preparation of samples for chromatography or electrofocusing.

Chromatography of the Sephadex G-50 eluate of the ammonium sulfate precipitate was performed on DEAE-Sephadex columns equilibrated with $5 \mathrm{mM}$ phosphate buffer, $\mathrm{pH} 8.0$, essentially according to Colman et al. (2) but using a $\mathrm{NaCl}$ gradient between $0.0-0.3 \mathrm{M} \mathrm{NaCl}$. Arginine esterase activity of samples and fractions from Sephadex columns were assayed spectrophotometrically at $253 \mathrm{~nm}$ us ing $\alpha-N$-benzoyl-L-arginine ethyl spectrophotometrically at $253 \mathrm{~nm}$ using $\alpha-\mathrm{N}$-benzoyl-L-arginine ethyl
ester (BAEE) as substrate (12) in $0.1 \mathrm{M}$ of $\mathrm{Na}_{2} \mathrm{HPO}_{4}-0.15 \mathrm{M}$ of $\mathrm{NaCl}$ ester (BAEE) as
buffer, $\mathrm{pH} 7.6$

Electrofocusing was carried out in siliconized glass tubes ( $4 \mathrm{~mm} \mathrm{i.d.)}$ by a standard method $(9)$. $5 \%$ polyacrylamide gels containing $0.75 \%$ ampholine (pH range of $5-8$ ) were made using $0.044 \%$ ammonium persulfate as the catalyst. The length of the gel was $72 \mathrm{~mm}$. The gel was supported at the bottom by a layer of cheese cloth. $0.75 \%$ ampholine in water was layered to a height of $26 \mathrm{~mm}$ over the top of the gel surface. The tube were mounted in a disc gel electrophoresis apparatus. The anode compartment contained $0.2 \%$ of $\mathrm{H}_{2} \mathrm{SO}_{4}$ and the cathode compartment contained $0.4 \%$ diethanolamine. The gel was pre-run at $200 \mathrm{v}$ at $4^{\circ} \mathrm{C}$ for
$\mathrm{hr}$ by which time the current fell to a steady value. Ammonium persulfate $1 \mathrm{hr}$ by which time the current fell to a steady
was removed from the gel by this pre-run.

After the pre-run, a mixture of $0.050 \mathrm{ml}$ of Sephadex eluate of the activated plasma and $0.050 \mathrm{ml}$ of $40 \%$ sucrose $(\mathrm{W} / \mathrm{v})$ was introduced unde the layer of ampholine. Electrofocusing was continued at $200 \mathrm{v}$ for $12 \mathrm{hrs}$ at $4^{\circ} \mathrm{C}$. The gels were stained for arginine esterase activity at $37^{\circ} \mathrm{C}$ essentially according to Fujimoto et al. (8). The composition of the staining solution was similar to that of Fujimoto et al. (8); however, the phenazine methosulfate concentration was raised ten-fold $(1 \mathrm{mg} / 30 \mathrm{ml}$ rather than $0.1 \mathrm{mg} / 30 \mathrm{ml}$ ). The gel was stained for $4 \mathrm{hrs}$ rather than $1 \mathrm{hr}$ to facilitate uniform staining, fixed for $1 \mathrm{hr}$ in methanol:acetic acid:water (5:1:5) and destained in 7\% acetic acid until the bands were clearly visible on a pale purple background.

\section{Results}

Chloroform-ellagic acid treated plasma can be clearly separated into two fractions of activities (Figure 1A) on DEAE-Sephadex columns. The first peak (I) which comprises over $60 \%$ of the total activity is completely inhibited by STI. The second peak (II) consists of arginine esterase activity which is almost totally resistant to inhibition by STI. This pattern of distribution of activities was consistently observed in all plasma samples from controls. The pattern of elution of arginine esterase activity from plasma samples of patients with CF is shown in Figure 1B. A reduction patients tested. The size of peak II was similar to that observed in controls.

Electrofocusing on polyacrylamide gels and subsequent staining for arginine esterase activity revealed seven bands in plasma samples from al controls (Figure 2). Six of these bands, designated A-F, represent arginine esterase activity, while the band $X$ is an artifact produced by the contact of sulfuric acid with the gel. A cluster of three bands called C, D, and $\mathrm{E}$ were observed at the center of the gel. These three bands are the most intense among the six bands. In plasma samples from all 11 patients with $C F$, only five arginine esterase bands were found. In 8 samples, band $\mathrm{D}$ was missing; in 2, band $\mathrm{E}$ was missing; and in 1 sample, band $\mathrm{C}$ was missing. These patterns were reproducible with all the plasma samples tested. Freezing and thawing of plasma, at least three times, did not alter the qualitative pattern of separation either in plasma from controls or from patients with CF. Electrofocusing of fraction 1 from DEAE-Sephadex columns revealed patterns of arginine esterase activity similar to whole plasma in both controls and patients with CF: the band missing in the DEAE-Sephadex column fraction from patients with CF corresponded to the band missing in the whole activated plasma from which it was derived. Plasma samples from 5 obligate heterozygotes showed patterns similax to plasma from controls.

\section{Discussion}

These data confirm and extend our previous observation of a deficiency of arginine esterase activity in saliva and plasma of patients with CF. Electrofocusing experiments on polyacrylamide gels further delineate the quantitative deficiency of arginine esterase activity to the absence of a single type of arginine esterase. In all CF cases studied, a single band of arginine esterase activity was absent. In the majority of patients, a specific band was missing; however, in some patients, a different band in the same narrow $\mathrm{pH}$ range of the gel was absent. This finding can be interpreted in a number of ways. One possibility is that of genetic heterogeneity. The possibility that $\mathrm{CF}$ may not be a single entity but rather a group of closely related genetic abnormalities with similar pathological a group of closely related genetic abnormalities with similar pathological
consequences has been discussed by many authors $(3,4,5)$. Studies of consequences has been discussed by many authors $(3,4,5)$. Studies of
individual families should clarify the uniqueness of the qualitative differences individual families should clarify the uniqueness of the qualitative differences
reported in this preliminary communication. Another possibility is that the reported in this preliminary communication. Another possibility is that the disaggregation of these enzymes. Further studies are needed to clarify cells of patients with cystic fibrosis should shed light on the specificity of our observation.

These findings are consistent with the hypothesis that a specific enzyme, in this case an arginine esterase, may be responsible for the numerous biochemical abnormalities which have been found in this disease. Hirschhorn $(10)$ has suggested that the anticiliary factor in serum of CF patients is a complex of the $\mathrm{C}-3 \mathrm{a}$ component of the complement system with immunoglobulin. In the normal individual, the arginine esterase could inactivate the complement. In the case of the CF patient, absence of the arginine esterase enzyme would result in the accumulation of the complex and would in some as yet undefined manner produce the clinical manifestations observed in $\mathrm{CF}$.

\section{$\underline{\text { Summary }}$}

Arginine esterase activity has been shown to be quantitatively and qualitatively different in plasma of patients with $C F$ when compared to agematched controls. This activity is significantly reduced in a specific eluate of plasma from CF patients when resolved by DEAE-Sephadex chromatography. In addition, qualitative alteration of arginine esterase activity, consisting of an absence of a single band of activity, has been found in plasma of patients with CF when studied by electrofocusing in polyacrylamide gels. Although the plasma of the majority of patients exhibited the absence of a Although the plasma of the majority of patients exhibited the absence of a
specific arginine esterase activity band, a number yielded deficiencies in specific arginine esterase activity band, a number yielded deficiencies in
other single bands within the same narrow pH region. These observations are consistent with the concept of genetic heterogeneity of the disease.

\section{References and Notes}

1. Bowman, B. H., McCombs, M. L., and Lockhart, L. H. : Cystic fibrosis: characterization of the inhibitor to ciliary action in oyster gills. Science $167: 871,1970$

2. Colman, R. W., Mattler, L., and Sherry, S. : Studies on prekallikrein (kallikreinogen) - kallikrein enzyme system from human plasma. I.
Isolation and purification of plasma kallikreins. J. Clin. Invest. $48: 23,1962$

3. Conover, J. H., Conod, E. J., and Hirschhorn, K.: Serum hexosaminidase levels in cystic fibrosis. Lancet $1: 1122,1973$.

4. Danes, B. S., and Bearn, A. G. : Cystic fibrosis of the pancreas. A study in cell culture. J. Exp. Med. 129:775, 1969.

5. Developments in cystic fibrosis research (Editorial). Lancet II:307, 1973. 
6. di Sant'Agnese, P. A., and Talamo, R. C.: Pathogenesis and physiopathology of cystic fibrosis of the pancreas. N. Engl. J. Med. 277:1287, 1343, 1399, 1967

7. Doggett, R. G., and Harrison, G. M. : Cystic fibrosis: in vitro reversal of the ciliostatic character of serum and salivary secretions by heparin. Nature, New Biology 243:251, 1973.

8. Fujimoto, Y., Moriya, H., Yamaguchi, K., and Morikawi, C. : Detection of arginine esterases of various kallikrein preparations on gellified electrophoretic media. J. Biochem. 71:751, 1972.

9. Haglund, H. : Isoelectric focusing in $\mathrm{pH}$ gradient -- a technique for fractionation and characterization of ampholyte. In "Methods of Biochemical Analysis." 19:1, 1971.

10. Hirschhorn, K.: Personal communication.

11. Mangos, J., and McSherry, N. R.: Studies on the mechanism of inhibition of sodium transport in cystic fibrosis of the pancreas. Pediat. Res. 2:378, 1968.

12. Rao, G. J. S., and Nadler, H. L. : Deficiency of trypsin-like activity in saliva of patients with cystic fibrosis. J. Pediat. 80:573, 1972.

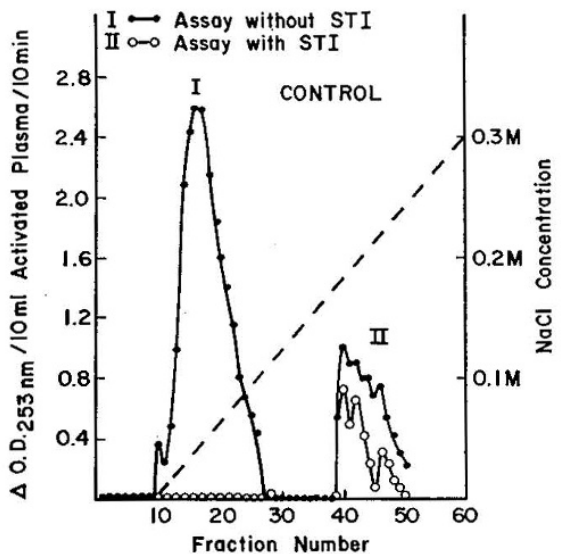

Fig. 1. A. Elution profile of arginine esterase activity in control plasma. B. Elution profile of arginine esterase activity in plasma of a patient with cystic fibrosis. $8.0 \mathrm{ml}$ of Sephadex G-50 eluate of the ammonium sulfate
precipitate (precipitate from about $2.5 \mathrm{ml}$ of citrated plasma) was applied

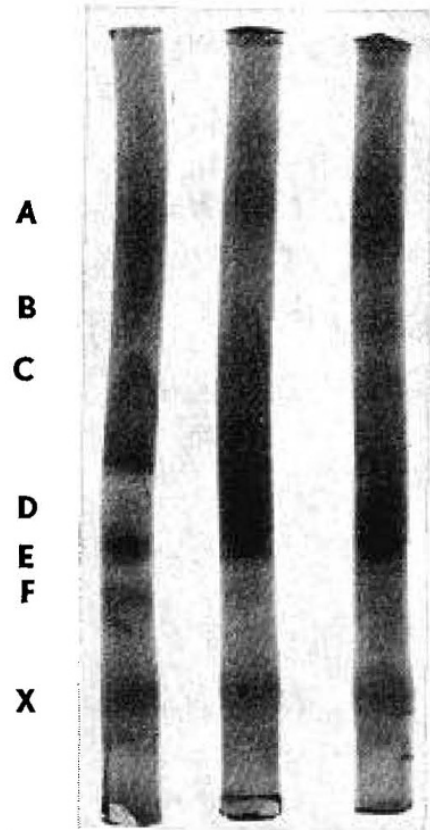

Fig. 2. A. Photograph of arginine esterases separated by polyacrylamide gel electrofocusing. The picture in the middle represents the pattern of control plasma. The pictures on either side of control represent patterns of plasma from two different patients with CF. B. Diagrammatic

Copyright O $_{0} 1974$ International Pediatric Research Foundation, Inc. 13. Rao, G. J. S., Posner, L. A., and Nadler, H. L.: Deficiency of $177: 610,1972$.

14. Spock, A., Heick, H. M. C., Cress, H., and Logan, W. S.: Abnormal serum factor in patients with cystic fibrosis of the pancreas. Pediat. Res. 1:173, 1967.

15. We thank Linda Posner and Greta Spells for excellent technical assistance and Dr. Lewis Gibson for help in obtaining the samples.

16. These studies were supported by grants from The National Institutes of Health HD 00036, The National Cystic Fibrosis Research Foundation, and the Helen Fay Hunter Trust

17. G. J. S. Rao is a Robert and Mary Wood Innovative Research Fellow.

18. H. L. Nadler is the Irene Heinz Given and John La Porte Given Research Professor of Pediatrics.

19. Requests for reprints should be addressed to: Henry L. Nadler, M.D Children's: Memorial Hospital, 2300 Children's Plaza, Chicago, Illinois 60614.

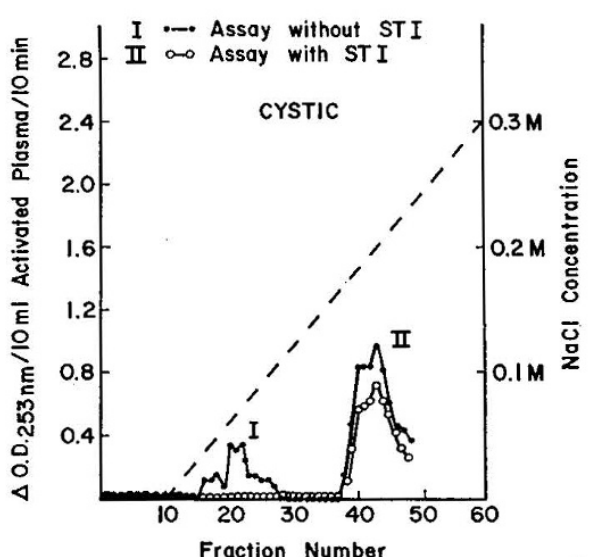

to a DEAE-Sephadex column $(0.9 \mathrm{~cm} \times 15.0 \mathrm{~cm})$. $3.0 \mathrm{ml}$ fractions were collected and assayed for activity. The dashed line represents the NaCl gradient.

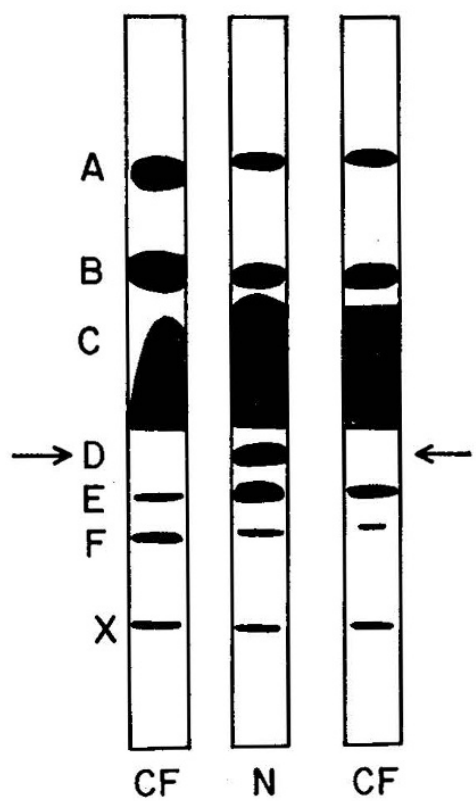

representation of the photograph in Fig. 2. A. Top: $0.4 \%$ diethanolamine $(-)$. Bottom: $0.2 \%$ sulfuric acid $(+)$. CF: CF plasma. $N$ : control plasma. The arrows represent the position of missing $\mathrm{D}$ band in both samples of CF plasma.

Printed in U.S.A. 